\title{
Aspects of Computer-Aided Tomography Scan (Cat) in the Child Intracranial Tumors in Abidjan: Report of 30 Cases
}

\author{
Ange Eric Zouzou ${ }^{1,2 *}$, Ange Patrick N'dja ${ }^{1,2}$, Alexis Kanga1,2, Debato Tina Gnaoulé1,2, \\ Kouamé Justin N'dah1,3, Lolo Diambra ${ }^{1,2}$, Alexis Konan ${ }^{1,2}$, Gogoua Casimir Gbazi, ${ }^{1,2}$ \\ ${ }^{1}$ Faculty of Medical Sciences of Abidjan, Felix Houphouet-Boigny University of Abidjan, Abidjan, Côte d'Ivoire \\ ${ }^{2}$ Department of Radiology, University Hospital of Cocody, Abidjan, Côte d'Ivoire \\ ${ }^{3}$ Department of Anatomical Pathology, University Hospital of Cocody, Abidjan, Côte d'Ivoire \\ Email: aegzouzou@gmail.com
}

Received 21 May 2016; accepted 20 June 2016; published 23 June 2016

Copyright (C) 2016 by authors and Scientific Research Publishing Inc.

This work is licensed under the Creative Commons Attribution International License (CC BY). http://creativecommons.org/licenses/by/4.0/

(c) (i) Open Access

\begin{abstract}
Aim: The aim of this study was to specify the various computed tomography aspects of the intracranial tumors of the child. Equipment and method: It was about a retrospective study carried out in 30 children (15 boys and 15 girls) aged from 3 to 15 years (medium age 8.3 years). All the patients were explored with the computed tomography scan. Sixteen lesions profited from an anatomopathologic analysis for which an anatomoradiologic correlation was obtained. Results: The scanner objectified a cerebral tumor in all the cases. Topography was supra-tentorial in 19 cases $(64 \%)$ and 11 cases $(36 \%)$ were under tentorial. Almost all the tumors were single $(96 \%$ of the cases) and were well limited ( $80 \%$ of the cases). The tumors were mixed in $50 \%$ of the cases with the presence of calcification in $66 \%$ of the cases. They were characterized by their large size $(3$ at $8 \mathrm{~cm}$ ) in $86 \%$ of the cases. The etiologies of the tumors were dominated by glioma in $50 \%$ of the cases and as a whole, the radio-histological correlation was good $(87.5 \%)$. Conclusion: Glial tumors are most frequent in the child. Computer-aided tomography scan represents here the focus of intracranial tumors diagnosis in the child. It must be carried out as a clinical suspicion to improve the diagnosis of these tumors.
\end{abstract}

\section{Keywords}

Cranium, Tumor, Child, CT

\footnotetext{
"Corresponding author.
}

How to cite this paper: Zouzou, A.E., N'dja, A.P., Kanga, A., Gnaoulé, D.T., N'dah, K.J., Diambra, L., Konan, A. and Gbazi, G.C. (2016) Aspects of Computer-Aided Tomography Scan (Cat) in the Child Intracranial Tumors in Abidjan: Report of 30 Cases. Advances in Computed Tomography, 5, 30-34. http://dx.doi.org/10.4236/act.2016.52003 


\section{Introduction}

Brain tumors in children are common and represent a quarter of solid tumors in children [1]. Their prognosis depends on the topography, the degree of aggressiveness and the size of the tumor [2]. Computed tomography (CT) plays a fundamental role in the diagnosis of these conditions and despite its use for ten years in Abidjan, the diagnosis is made at the stage of a large tumor mass darkening the prognosis of these diseases. In this work, we present the aspects and features of CT brain tumors encountered in the pediatric age in our daily practice.

\section{Material and Methods}

Scientific medical management of the hospital approved this retrospective study.

This is a retrospective study based on the medical records of neurosurgery patients at Yopougon University Hospital from 2001 to 2008.

During this period, thirty cases of children with brain tumors diagnosed on CT were analyzed. The study focused on the age of the occurrence of the tumor, the consultation period, the clinical manifestations, the computed tomography as well as the anatomical characteristics of the tumor masses.

The CT scans were performed in contiguous axial slices millimeter before and after contrast injection on a Somatom type multi-detector unit labeled SIEMENS.

It was noted the number, topography, size, extent and nature of the tumor to provide an etiological diagnosis.

Sixteen patients underwent a lumpectomy; the surgical specimens were analyzed in an anatomo-pathology. A radio-histologic correlation was established between the radiological hypothesis and the result of the anatomo-pathology.

Statistical analysis of the data was performed using epi info Version 3.1.1 software.

\section{Results}

The average age of our patients was 08 , three years, ranging from 03 years to 15 years. The two sexes were involved in the same proportion (15 boys and 15 girls). Two frequency peaks were observed between 5 years and 9 years and between 10 and 15 years.

The average time of consultation was 05.82 months after the onset of clinical manifestations.

Among these clinical signs, was the intracranial hypertension syndrome (ICHT), 86.7\% was the most frequent followed by gait disorders (33\%) and language disorders (20\%).

The physical examination showed that, visual disturbances (67\%), pyramidal (56\%) and cerebral (33\%) syndromes were the most observed anomalies. The CT scan pointed out a unique tumor in 29 patients (96\%), in one case, two tumor foci were observed.

The seat was supra-tentorial in 19 (64\%) and sub-tentorial in 11 cases (37\%). The tumors were mixed (tissue and fluid) in $50 \%$ of the cases, spontaneously they were hyper compact in nine cases, hypo compact in five cases and iso-compact in one case.

The limits were clear in $80 \%(n=24$ cases) and unclear in six cases. Fifteen of these lesions were between 3 and $5 \mathrm{~cm}$, eleven had a diameter of 6 to $8 \mathrm{~cm}$. Two tumors were less than $2 \mathrm{~cm}$ and two measured more than 8 $\mathrm{cm}$. Twenty $(\mathrm{n}=20)$ tumors contained calcifications mostly macro calcifications (Figure 1$)$. These tumors were heterogeneously enhancing in $33 \%$ of the cases $(n=10)$ and the contrast enhancement was made in a form of crown in six cases (20\%). It was missing in three cases. The associated lesions were represented by ventricular dilation 23 cases (76\%), the died edema tumor in five cases and five cases of cerebral involvement.

After the radiological analysis, we grasped 15 cases as glial tumors, five cases as cranio-pharyngiomas (Figure 1) and five cases as medullo-blastomas (Figure 2). The anatopathological examination of parts 16 highlighted seven glial tumors (Figure 3).

Two diagnoses were discordant after anatomic correlation-radiation.

A glioma was taken for medullo-blastoma (Figure 4) and one adenoma for a cranio-pharyngioma.

\section{Discussion.}

The peaks of the occurrence of brain tumors in children in our study are consistent with the literature data. It affects girls and boys in the same proportions [3]-[5].

Clinically, ICHT is the circumstance of the most common finding ( $87 \%$ in our study) or $100 \%$ of cases when 

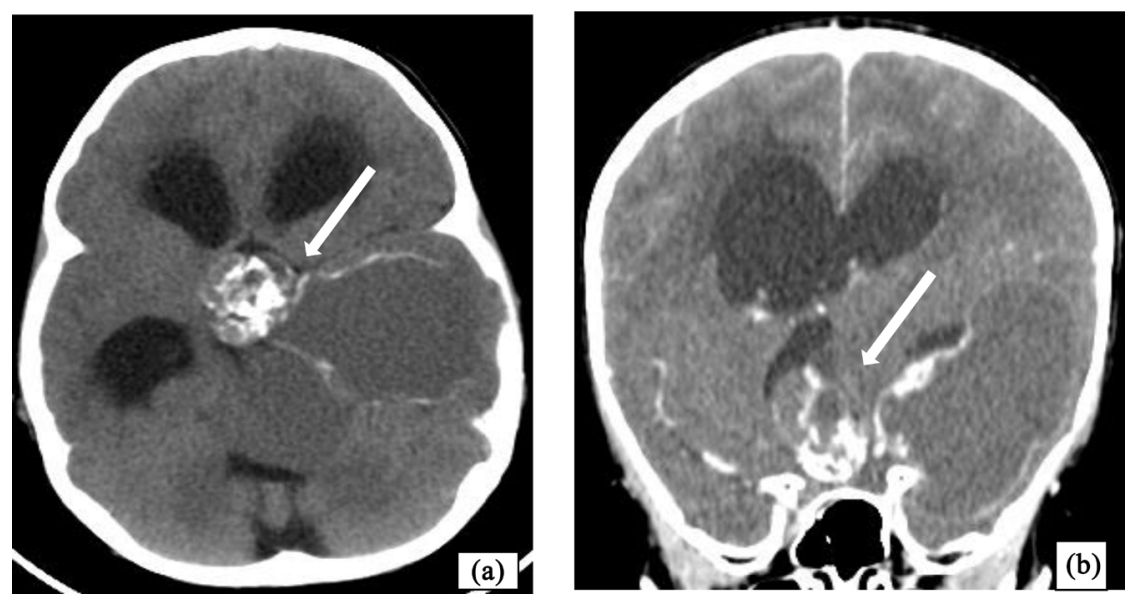

Figure 1. Cranial pharyngioma: CT axial section (a) and coronal (b) without and after an intravenous injection of a product of contrast. Mixed cystic mass and calcified tissue of the sella area propagated at the left temporal lobe of the third ventricle with hydrocephalus (arrow indication).

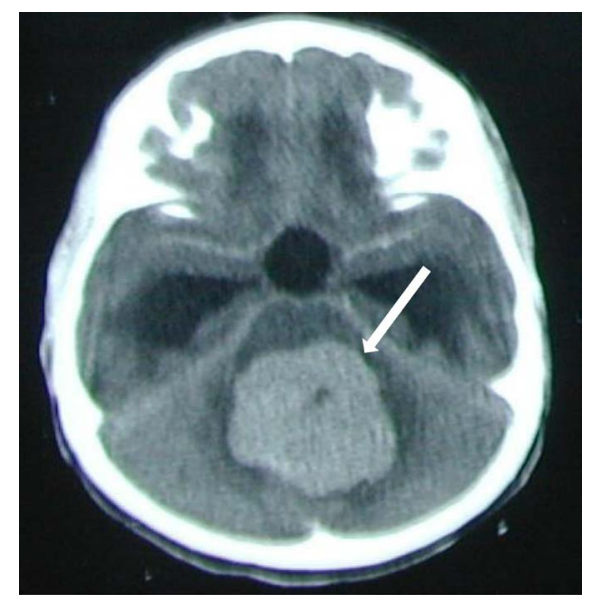

Figure 2. Medullo-blastoma: after CT axial section with an intravenous injection of a product of contrast. Good solid masse, homogeneous and well limited. A compressive vermian taking intensely the contrast: compression of the fourth ventricle with hydrocephalus (arrow indication).

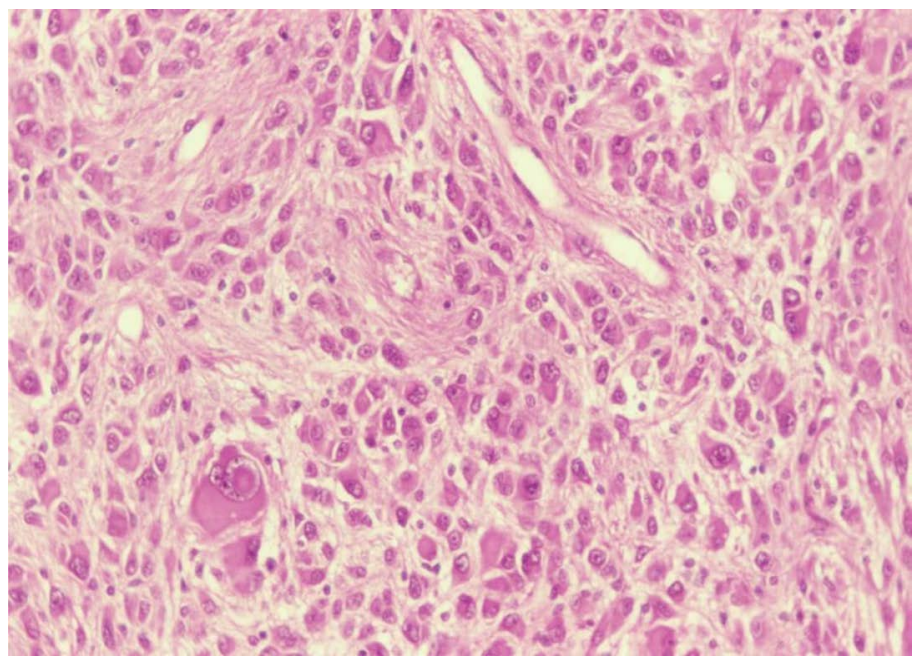

Figure 3. $(\mathrm{HE} \times 25)$ : astrocytoma cells with sometimes great jumbo sizes and/or multinucleated, eosinophilic cytoplasm. 


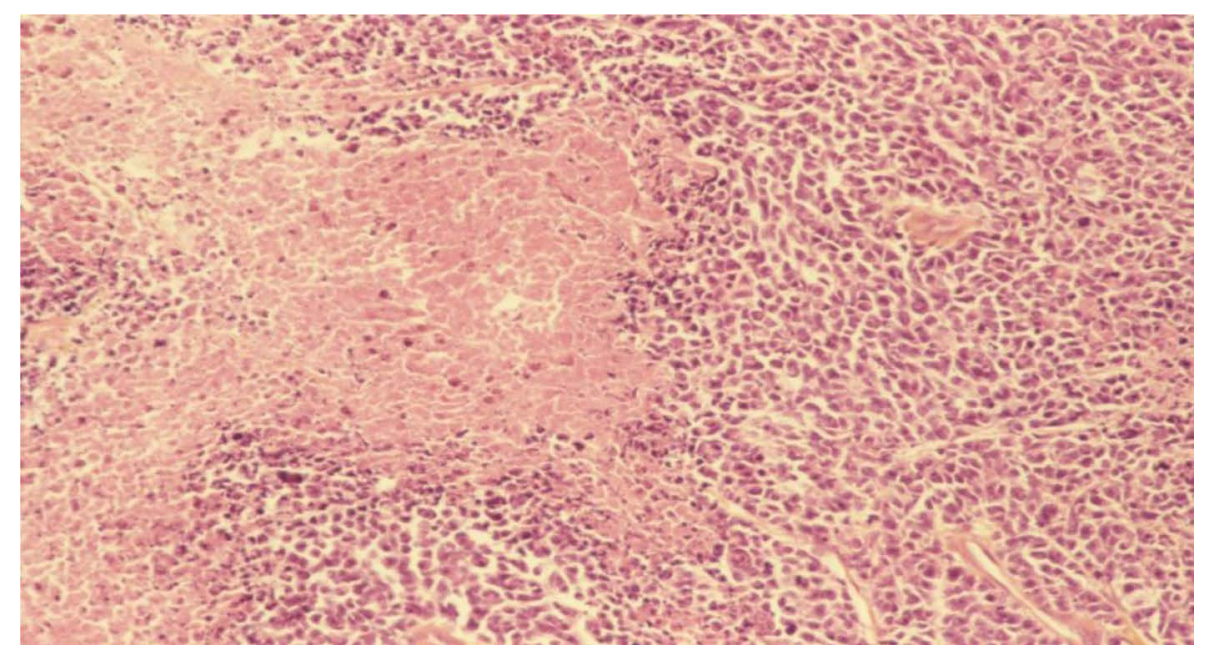

Figure 4. (HES ×10): medulloblastoma (poorly differentiated neuroepithelial cells with necrosis).

the tumor is located in the posterior trench [4]. These tumors are frequently associated with a ventricular dilatation, which is the result of a large volume of tumor [2].

Unlike to the literature data [1] [6] [7], which show a predominant sub-tentorial topography, our study has revealed a supra-tentorial topography in $64 \%$ of the cases. This is not a peculiarity of brain tumors in Ivorian children because a study carried out in Abidjan under the same conditions had revealed a sub-tentorial preferential topography [4]. In our case we can attribute this finding to the law of series.

We found unique tumors (96\%) as in the study of Couanet [1].

The average long consultation time was 05 months with an extreme ranging from 1 to 12 months contrary to western series [4].

The consequence of the long delay in consulting is the discovery of voluminous masses of tumor at the time of the initial CT examination which is responsible for serious mechanical injuries (engagement and ventricular dilation).

The delay in the consultation is the mark of African oncological studies [7].

Apart from this ascertainment, the behavior of the tumor masses after the injection of the product of contrast and the appearance of calcified or mixed tumors are the same aspects described by most Western authors [1].

Histological presumption of imaging tumors is based on epidemiological and topographic data and on calcic based or not tumors.

These criteria allowed us to mention 15 cases of gliomas, six cases of medulloblastomas and five cases of craniopharyngiomas.

Sixteen patients in our series benefited from a lumpectomy; which permitted us to correlate the presumptions of the CT with the results of the anatomopathology.

This confrontation CT/histology identified two diagnostic discrepancies.

An adenoma was mistaken for a craniopharyngioma. The cystic character of the adenoma which is usually homogeneous, is probably related to a necrosis and it was responsible of that confusion especially as the calcicless Craniopharyngiomas components are described in the literature [1].

The second case of mismatch is related to a sub-tentorial location of aglioma which was mistaken with a medulloblastoma knowing that the medulloblastoma is the most common tumor in the sub-tentorial stage. It is in these situations that MRI plays a fundamental role in the characterization of the fleshy and cystic components of the masses able to refine the etiologic diagnosis [1].

Although this method of exploration is available in Abidjan, it still is unfortunately not well integrated into the exploration of brain tumors on account of its high cost the majority of our patients cannot afford.

\section{Conclusion}

Intracranial tumors in children are common and affect both sexes picking between 5 and 9 years and between 10 and 15 years. Their CT aspects are described by most Western authors. They distinguish themselves in our study 
by their large size at the time of the diagnosis that accounts for the existence of associated lesions (hydrocephalus and engagement). In this context, although the scanner is performant, it is limited to the assessment of the lesions with no real benefit to the patient's surgical care.

\section{Conflict of Interest}

The authors report no conflict of interest.

\section{References}

[1] Couanet, D. and Adamsbaum, C. (2006) Imagerie des tumeurs cérébrales de l'enfant. Journal de Radiologie, 87, 732-747. http://dx.doi.org/10.1016/S0221-0363(06)74084-7

[2] Rochette-Paris, M., Kremer, S., Taillander, L., Moret, C., Schmitt, E., Bracard, S., et al. (2004) Tumeurs cranio encéphalique. Technique d’imagerie et semiologie. EMC-Radiologie, 1, 604-620. http://dx.doi.org/10.1016/j.emcrad.2004.09.001

[3] Alliez, B., Gueye, M. and Ducolombier, A. (1987) Tumeurs cérébrale chez l’enfant: Expérience africaine 79 observations anatomo cliniques. Médecine et Armées, 15, 309-312.

[4] Sokolo (1982) Tumeurs de la fosse postérieure chez l'enfant: Aspects tomodensitométriques. Thèse de Médecine, Abidjan.

[5] Chastagner, P., Marchal, J.C. and Baylac, F. (1998) Les gliomes de bas grade de l'enfant: analyse portant sur une expérience unicentrique de 21 patients. Annales de Pédiatrie, 45, 192-200.

[6] Raybaud, C., et al. (1989) Cancer de l'enfant (les tumeurs du SNC). Flammarion, Paris, 539-568.

[7] N'Dri, K., et al. (2006) Aspects radiologiques des tumeurs et pseudotumeurs de la mandibule à propos de 47 cas. Journal Africain d'Imagerie Médicale, 3, 187-191.

\section{Submit or recommend next manuscript to SCIRP and we will provide best service for you:}

Accepting pre-submission inquiries through Email, Facebook, Linkedin, Twitter, etc A wide selection of journals (inclusive of 9 subjects, more than 200 journals)

Providing a 24-hour high-quality service

User-friendly online submission system

Fair and swift peer-review system

Efficient typesetting and proofreading procedure

Display of the result of downloads and visits, as well as the number of cited articles

Maximum dissemination of your research work

Submit your manuscript at: http://papersubmission.scirp.org/ 